\title{
Renal and Cardiovascular Effects of Sodium Glucose Co-Transporter 2 Inhibitors in Patients with Type 2 Diabetes and Chronic Kidney Disease: Perspectives on the Canagliflozin and Renal Events in Diabetes with Established Nephropathy Clinical Evaluation Trial Results
}

\author{
Matthew R. Weir ${ }^{a}$ Peter A. McCullough ${ }^{b} \quad$ John B. Buse ${ }^{c} \quad$ John Anderson ${ }^{d}$ \\ a Division of Nephrology, Department of Medicine, University of Maryland School of Medicine, Baltimore, MD, USA; \\ ${ }^{b}$ Baylor University Medical Center, Baylor Heart and Vascular Hospital, Baylor Heart and Vascular Institute, Dallas, TX, \\ USA; ' University of North Carolina School of Medicine, Chapel Hill, NC, USA; dThe Frist Clinic, Nashville, TN, USA
}

\section{Keywords}

Sodium glucose co-transporter 2 inhibitor .

Type 2 diabetes · Chronic kidney disease .

Cardiovascular disease $\cdot$ Randomized trials

\begin{abstract}
Background: Chronic kidney disease (CKD) risk is elevated in patients with type 2 diabetes mellitus (T2DM). Disease management in these patients has been generally focused on glycemic control and controlling other renal and cardiac risk factors as, historically, few protective therapies have been available. The Canagliflozin and Renal Events in Diabetes with Established Nephropathy Clinical Evaluation (CREDENCE) trial of canagliflozin was the first study to demonstrate renal protection with a sodium glucose co-transporter 2 inhibitor in patients with T2DM and CKD, and these results could have important implications for clinical practice. Summary: In CREDENCE, participants with T2DM and estimated glomerular filtration rate $30-<90 \mathrm{~mL} / \mathrm{min} / 1.73 \mathrm{~m}^{2}$
\end{abstract}

and urinary albumin-creatinine ratio $>300-5,000 \mathrm{mg} / \mathrm{g}$ who were treated with an angiotensin-converting enzyme inhibitor or angiotensin receptor blocker for $\geq 4$ weeks prior to randomization at either the maximum labeled or tolerated dose were randomized to receive either canagliflozin $100 \mathrm{mg}$ or placebo. Canagliflozin significantly reduced the risk of the primary composite outcome of doubling of serum creatinine, end-stage kidney disease, or renal or cardiovascular (CV) death compared with placebo (hazard ratio $0.70,95 \% \mathrm{Cl}$ $0.59-0.82 ; p=0.00001$ ). Canagliflozin also reduced the risk of secondary renal and CV outcomes. The safety profile of canagliflozin in CREDENCE was generally similar to previous studies of canagliflozin. No imbalances were observed between canagliflozin and placebo in the risk of amputation or fracture in the CREDENCE population. Key Messages: The positive renal and CV effects of canagliflozin observed in the CREDENCE trial could have a substantial impact on improving outcomes for patients with T2DM and CKD.

(c) 2020 S. Karger AG, Basel

\section{KARGER}

(C) 2020 S. Karger AG, Basel

karger@karger.com

www.karger.com/ajn
Matthew R. Weir, MD

Division of Nephrology, Department of Medicine

University of Maryland School of Medicine

22 S. Greene Street, Room N3W143, Baltimore, MD 21201 (USA)

E-Mail mweir@medicine.umaryland.edu 


\section{Introduction}

Burden and Mechanisms of Chronic Kidney Disease

Chronic kidney disease (CKD) is defined by the Kidney Disease: Improving Global Outcomes working group as abnormalities of kidney structure or function present for $>3$ months, with implications for health. The Kidney Disease: Improving Global Outcomes CKD risk score is classified based on estimated glomerular filtration rate (eGFR) and albuminuria [1]. The prevalence of CKD has been estimated to be between 10 and 13\% globally and $14.8 \%$ in the United States and is expected to increase due to the aging global population and rising prevalence of diabetes and hypertension $[2,3]$.

CKD affects approximately $40 \%$ of patients with type 2 diabetes mellitus (T2DM), and diabetes is the leading cause of CKD [3]. It is recommended that all patients with T2DM have urinary albumin-creatinine ratio (UACR) and eGFR screenings annually because progression to substantial proteinuria (protein excretion $>300 \mathrm{mg} / \mathrm{g}$ ) is a strong predictor of rapid progression of CKD to end-stage kidney disease (ESKD). Despite this, CKD awareness among health care providers is low, which can be a barrier to providing effective care; in the United States, $48 \%$ of those with severely reduced kidney function who are not on dialysis are unaware that they have CKD $[4,5]$.

Unlike cardiovascular (CV) disease, for which many cardioprotective medications are available, physicians have limited treatment options beyond glycemic control and antihypertensive therapy to slow CKD progression. There have been no new treatments in 18 years, since the development of renin-angiotensin-aldosterone system (RAAS) inhibitors, including angiotensin-converting enzyme (ACE) inhibitors and angiotensin receptor blockers (ARBs), leaving a substantial residual risk for renal failure to occur $[6,7]$.

Several key potentially modifiable factors, including obesity, hyperglycemia, and systemic hypertension, may work together to drive maladaptive processes, such as insulin resistance, glomerular hyperfiltration, inflammation, proteinuria, and $\mathrm{CV}$ disease, that contribute to the development and progression of CKD in patients with T2DM. Additionally, patients with CKD are at an increased risk for several safety concerns as a result of their progressive renal insufficiency, including hypoglycemia, hyperlipidemia, hypertension, hyperkalemia, hyperphosphatemia, hyperuricemia, anemia, fluid retention and heart failure, metabolic bone disease, amputation, and altered drug clearance [8-13].

Canagliflozin in Type 2 Diabetes and CKD

\section{Current Treatment Options for Patients with T2DM} and $C K D$

Treatment for patients with T2DM and CKD aimed at reducing the rate of progression to ESKD is limited to management of underlying risk factors, including hypertension, dyslipidemia, and hyperglycemia, and limiting dietary protein intake [14-16]. In patients with hypertension, reducing blood pressure (BP) to $<140 / 90 \mathrm{~mm} \mathrm{Hg}$ is recommended to slow $\mathrm{CKD}$ progression, though a target of $<130 / 80 \mathrm{~mm} \mathrm{Hg}$ may be appropriate for some patients, and treatment with an ACE inhibitor or ARB is recommended [16]. At least annual screening of creatinine, eGFR, and UACR is recommended for patients with T2DM, and monitoring of electrolytes, eGFR, and UACR should be more frequent after a diagnosis of CKD [16].

The current treatment paradigm for managing renal outcomes in patients with T2DM and CKD is largely based on results from 2 landmark trials of ARBs: Reduction of Endpoints in NIDDM with the Angiotensin II Antagonist Losartan Study (RENAAL) and Irbesartan Diabetic Nephropathy Trial (IDNT) [6, 7]. In RENAAL, treatment with losartan was associated with a $16 \%$ reduction in the risk of the composite outcome of doubling of serum creatinine, ESKD, or death compared with placebo in patients with T2DM and nephropathy [6]. In IDNT, treatment with irbesartan reduced the risk of a composite outcome of doubling of serum creatinine, ESKD, or death with irbesartan by $20 \%$ compared with placebo and by $23 \%$ compared with amlodipine (a calcium channel blocker) in patients with hypertension, T2DM, and proteinuria [7].

Though RAAS inhibitors can ameliorate hypertension and hyperfiltration, only 3 agents are indicated for the treatment of nephropathy in patients with diabetes (i.e., captopril for type 1 diabetes mellitus [T1DM]; losartan and irbesartan for T2DM) [17-19]. Consistent effects on ESKD endpoints are not observed across all RAAS inhibitors, and these agents are not thought to affect hyperglycemia or obesity and do not reduce the risk of CV outcomes, independent of BP control [20]. However, not all agents have been studied, and there may be differences based on dose. Furthermore, increased risk of hyperkalemia and changes in serum creatinine are viewed as safety concerns by clinicians [21]. Additionally, despite a $22 \%$ reduction in the risk of doubling of serum creatinine or renal replacement therapy, meta-analytic results suggest that as a class, RAAS inhibitors do not significantly reduce the risk of ESKD [22, 23]. However, these observations need to be tempered because not all 
studies were adequately powered to examine this endpoint.

One observational study of patients with T2DM and stages $3 / 4$ CKD showed that $84 \%$ are being treated with RAAS inhibitors and only $26 \%$ are being treated with the maximum dose [24]. Thus, either undertreatment or the inability to tolerate the maximum dose of a RAAS inhibitor may contribute to higher risk of CKD progression in people with T2DM and CKD, especially as the severity of CKD worsens [25]. In addition, even when patients are treated with the maximum dose of a RAAS inhibitor, there is still a high residual risk of progression of CKD [20]. In light of these observations, new treatments are needed that can slow CKD progression, studied in properly designed trials of patients with CKD [26].

Renaleffectsofsodiumglucoseco-transporter2(SGLT2) inhibitors were suggested in CV outcomes trials (CVOTs) of patients with T2DM and high CV risk [27-29]. The Canagliflozin and Renal Events in Diabetes with Established Nephropathy Clinical Evaluation (CREDENCE) trial of canagliflozin has provided the first definitive evidence of renal protection with an SGLT2 inhibitor in patients with T2DM and CKD. This article reviews the evidence for the effects of SGLT2 inhibitors on renal outcomes, with a focus on the results from CREDENCE and the implications for clinical practice.

\section{Defining Renal Endpoints in Patients with CKD}

Due to variability in CKD progression, it can be challenging to measure the impact of new therapies on renal outcomes, even in high-risk populations [30]. In addition to hard renal outcomes like ESKD and renal death, surrogate endpoints like the doubling of serum creatinine (roughly equivalent to a 57\% reduction in eGFR) and albuminuria have been used in clinical trials of patients with CKD. However, there may be some limitations associated with these endpoints because accumulating a reasonable number of these events requires large numbers of patients and long follow-up duration, and changes in surrogate endpoints do not always correlate with hard renal outcomes [30-35]. Additionally, albuminuria alone is not considered a surrogate endpoint because it does not predict the endpoint of interest and is subject to high levels of variance $[36,37]$. Although there is ongoing work on identifying novel renal endpoints to predict progression to ESKD [38], clinically meaningful renal outcomes, such as ESKD, remain important to definitively demonstrate renal benefits in patients with T2DM and CKD [39].
Supporting Renal Evidence from Large Outcomes

Trials of SGLT2 Inhibitors

The CVOTs of SGLT2 inhibitors (Empagliflozin, Cardiovascular Outcomes, and Mortality in Type 2 Diabetes [EMPA-REG OUTCOME] trial of empagliflozin, CANagliflozin cardioVascular Assessment Study [CANVAS] Program trials of canagliflozin, and Dapagliflozin Effect on Cardiovascular Events [DECLARE] trial of dapagliflozin) were designed to evaluate CV safety for the endpoints of nonfatal myocardial infarction, nonfatal ischemic stroke, and CV death in patients with T2DM and either prevalent $\mathrm{CV}$ disease or high risk for $\mathrm{CV}$ events. Though the populations in these studies did not have high proportions of patients with CKD $(<26 \%$ of patients had eGFR $<60 \mathrm{~mL} / \mathrm{min} / 1.73 \mathrm{~m}^{2}$ and $<12 \%$ of patients had UACR $>300 \mathrm{mg} / \mathrm{g}$ ) and were not powered for renal outcomes, positive effects on renal outcomes were demonstrated in EMPA-REG OUTCOME [28], the CANVAS Program [27], and DECLARE [29].

While participants had low renal risk, these results suggested that SGLT2 inhibitors may provide reductions in the risk of renal composite endpoints compared with placebo (Table 1). Variation in baseline renal function and the endpoints selected are likely largely responsible for the differences in renal outcomes among these CVOTs [40]. Furthermore, renal endpoints in these trials were exploratory.

The effects of dapagliflozin were also studied in the Dapagliflozin and Prevention of Adverse Outcomes in Heart Failure (DAPA-HF) trial of patients with heart failure and reduced ejection fraction, which included those with and without diabetes. A higher proportion of patients in DAPA-HF had renal impairment $(41 \%$ had eGFR $<60 \mathrm{~mL} / \mathrm{min} / 1.73 \mathrm{~m}^{2}$ ) compared with the CVOTs, and dapagliflozin showed a positive effect on the renal outcome of $\geq 50 \%$ eGFR reduction, ESKD, or renal death (hazard ratio [HR] 0.71, 95\% CI 0.44-1.16) [41].

\section{Renal Outcomes with Canagliflozin in Patients with T2DM and CKD in the CREDENCE Trial}

The CREDENCE trial was the first dedicated renal outcomes trial of an SGLT2 inhibitor designed for patients with T2DM and CKD who were receiving clinically appropriate RAAS inhibition and powered for renal endpoints [42]. The CREDENCE trial, which was conceived in 2012 and enrolled its first patient in early 2014 prior to data availability from any CVOTs, provided the first efficacy and safety data for a population with T2DM and CKD that was not selected based on their CV risk.

CREDENCE enrolled patients $\geq 30$ years of age with T2DM, glycated hemoglobin A1c (HbA1c) $\geq 6.5-\leq 10.5 \%$, 
Table 1. Renal outcomes from CVOTs of SGLT2 inhibitors [27-29, 89, 90]

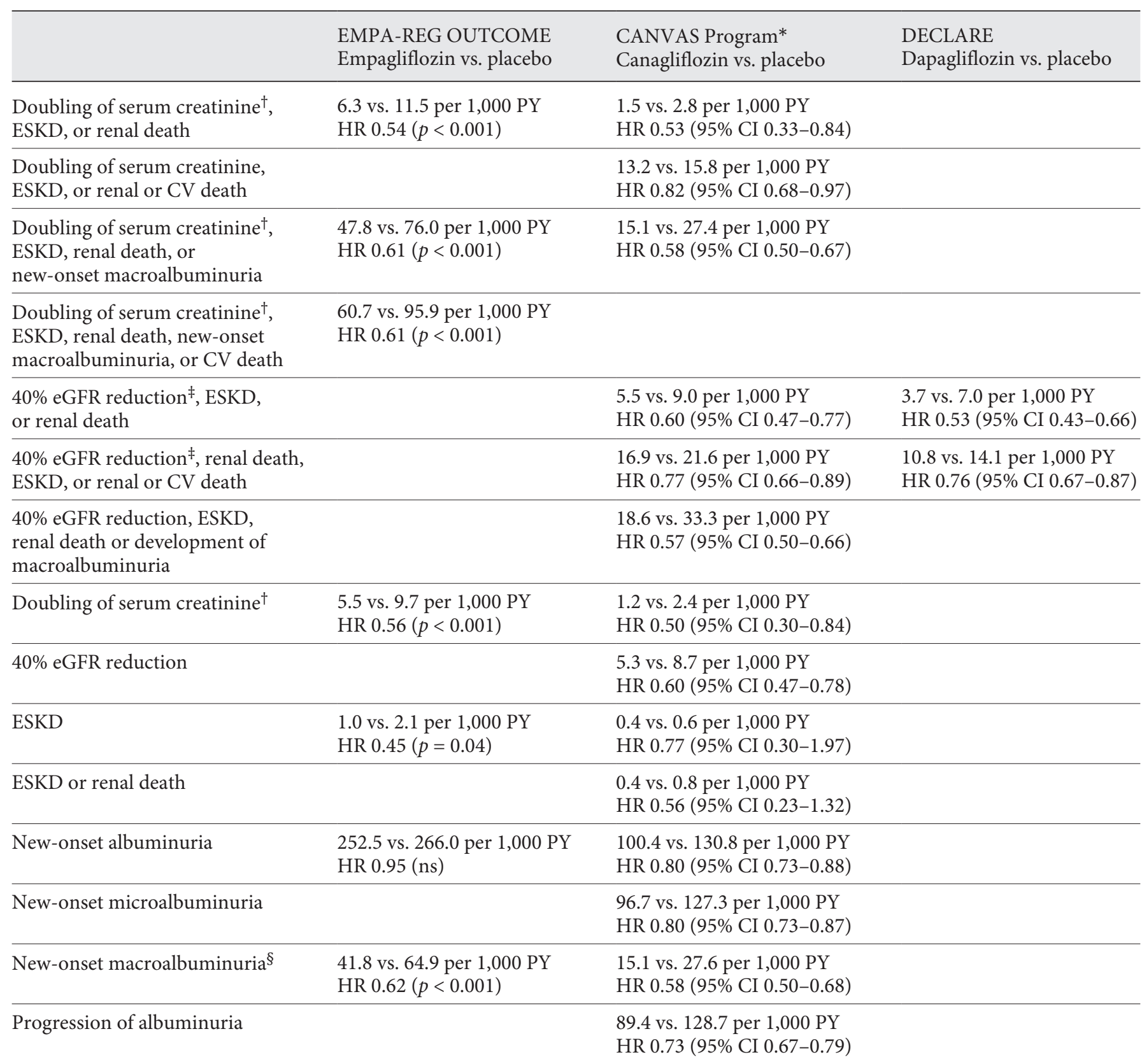

\footnotetext{
* While prespecified, the renal outcomes reported for the CANVAS Program are outside the formal hypothesis testing sequence; therefore, no $p$ values are reported.

† With eGFR $\leq 45 \mathrm{~mL} / \mathrm{min} / 1.73 \mathrm{~m}^{2}$ in EMPA-REG OUTCOME.

\# With eGFR $<60 \mathrm{~mL} / \mathrm{min} / 1.73 \mathrm{~m}^{2}$ in DECLARE.

$\S$ UACR $>300 \mathrm{mg} / \mathrm{g}$ with a UACR in EMPA-REG OUTCOME.

CVOT, cardiovascular outcomes trial; SGLT2, sodium glucose co-transporter 2; EMPA-REG OUTCOME, Empagliflozin, Cardiovascular Outcomes, and Mortality in Type 2 Diabetes; CANVAS, CANagliflozin cardioVascular Assessment Study; DECLARE, Dapagliflozin Effect on Cardiovascular Events; ESKD, end-stage kidney disease; PY, patient-years; HR, hazard ratio; CV, cardiovascular; eGFR, estimated glomerular filtration rate; ns, not significant; UACR, urinary albumin-creatinine ratio.
} 
Fig. 1. Effects of canagliflozin on (a) the primary composite outcome of ESKD, doubling of serum creatinine, or renal or CV death in the overall CREDENCE population [43], (b) renal, CV, and mortality outcomes in primary and secondary prevention cohorts [44], and (c) renal, CV, and mortality outcomes in subgroups defined by screening eGFR [45]. a From Perkovic et al. [43]. Copyright (c) 2019 Massachusetts Medical Society. Reprinted with permission from Massachusetts Medical Society. b Reprinted with permission from Mahaffey et al. [44]. * Exploratory outcome. ESKD, end-stage kidney disease; $\mathrm{CV}$, cardiovascular; CREDENCE, Canagliflozin and Renal Events in Diabetes with Established Nephropathy Clinical Evaluation; eGFR, estimated glomerular filtration rate; HR, hazard ratio; PY, patient-years.

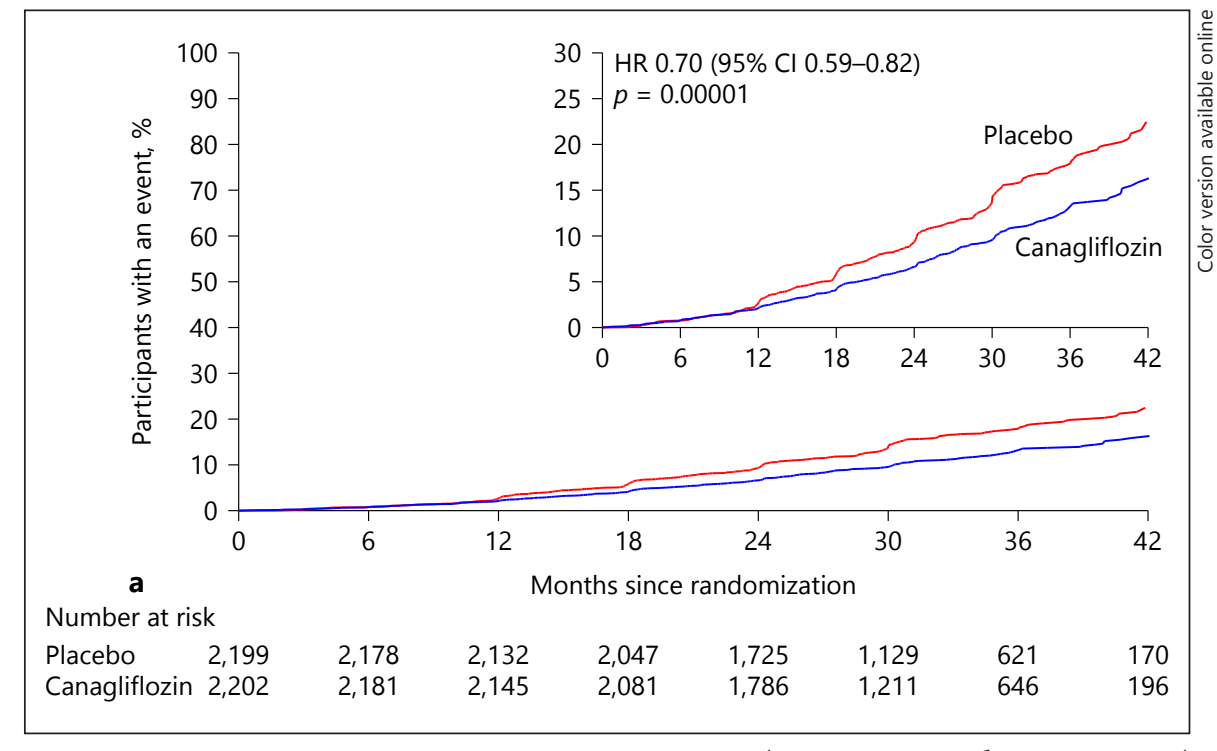

(Figure continued on next pages.) and CKD (defined as eGFR $30-<90 \mathrm{~mL} / \mathrm{min} / 1.73 \mathrm{~m}^{2}$ and albuminuria [UACR $>300-5,000 \mathrm{mg} / \mathrm{g}$ ]) [43]. Patients were required to be on an ACE inhibitor or ARB for $\geq 4$ weeks prior to randomization at either the maximum labeled or tolerated dose. A total of 4,401 patients were randomized to canagliflozin $100 \mathrm{mg}$ or placebo. At baseline, patients had a mean age of 63 years, HbAlc of $8.3 \%$, eGFR of $56.2 \mathrm{~mL} / \mathrm{min} / 1.73 \mathrm{~m}^{2}$, and median UACR of $927.0 \mathrm{mg} / \mathrm{g}$. About half (50.4\%) of patients had a history of CV disease and $14.8 \%$ had a history of heart failure.

The primary outcome of CREDENCE was the composite of doubling of serum creatinine, ESKD (requirement for renal replacement therapy in the form of chronic dialysis or transplantation or sustained eGFR $<15 \mathrm{~mL} /$ $\mathrm{min} / 1.73 \mathrm{~m}^{2}$ ), and renal or CV death. Canagliflozin treatment was associated with a $30 \%$ lower relative risk of the primary outcome compared with placebo (HR 0.70, 95\% CI $0.59-0.82 ; p=0.00001$; Fig. 1a), with all components of the composite contributing to the outcome [43]. Consistent effects on the primary outcome were observed across prespecified subgroups including by screening eGFR $\left(30-<45,45-<60\right.$, and $\left.60-<90 \mathrm{~mL} / \mathrm{min} / 1.73 \mathrm{~m}^{2}\right)$ and baseline UACR $(\leq 1,000$ or $>1,000 \mathrm{mg} / \mathrm{g})$ at baseline, independent of effects on HbAlc. In exploratory analyses of the components of the primary outcome, canagliflozin treatment was associated with a $32 \%$ reduction in ESKD (HR 0.68, 95\% CI 0.54-0.86; $p=0.002$ ) and a reduction in dialysis, kidney transplantation, or renal death (HR 0.72, 95\% CI 0.54-0.97). Canagliflozin reduced the risk of the secondary renal composite outcome of doubling of serum creatinine, ESKD, or renal death (HR 0.66, 95\% CI 0.53-
$0.81 ; p<0.001$; Fig. 1b) [43]. In addition to the effects on renal outcomes, canagliflozin was also associated with reductions in the CV composite outcomes of CV death or hospitalization for heart failure (HR 0.69, 95\% CI 0.57$0.83 ; p<0.001)$; CV death, myocardial infarction, or stroke (HR 0.80, 95\% CI 0.67-0.95; $p=0.01$ ); and hospitalization for heart failure (HR 0.61, 95\% CI $0.47-0.80 ; p<0.001$; Fig. 1b) [43]. In the overall population, the number needed to treat for 2.5 years to prevent 1 event was 22 for the primary composite outcome; 28 for the ESKD, doubling of serum creatinine, or renal death; 43 for ESKD; 46 for hospitalization for heart failure; 29 for CV death or hospitalization for heart failure; and 40 for $\mathrm{CV}$ death, nonfatal myocardial infarction, and nonfatal stroke $[43,44]$. The effects of canagliflozin on renal and CV outcomes, including the primary renal outcome and the composite of $\mathrm{CV}$ death, myocardial infarction, or stroke, were consistent in subgroups of participants with and without prior CV disease (Fig. 1b); canagliflozin was the first treatment to show a benefit for the composite of nonfatal myocardial infarction, nonfatal stroke, or CV death in primary prevention patients with T2DM and CKD [44]. The effects of canagliflozin on renal and CV outcomes were also consistent in subgroups by screening eGFR $(30-<45,45-<60$, and $60-<90 \mathrm{~mL} / \mathrm{min} / 1.73 \mathrm{~m}^{2}$; all $p$ for heterogeneity $\geq 0.11$; Fig. 1c) [45]. Although CREDENCE participants had eGFR $30-<90 \mathrm{~mL} / \mathrm{min} / 1.73 \mathrm{~m}^{2}$ at screening, 174 patients had eGFR $<30 \mathrm{~mL} / \mathrm{min} / 1.73 \mathrm{~m}^{2}$ at baseline; the effects of canagliflozin on renal and mortality outcomes in these participants were consistent with the overall population [46]. 


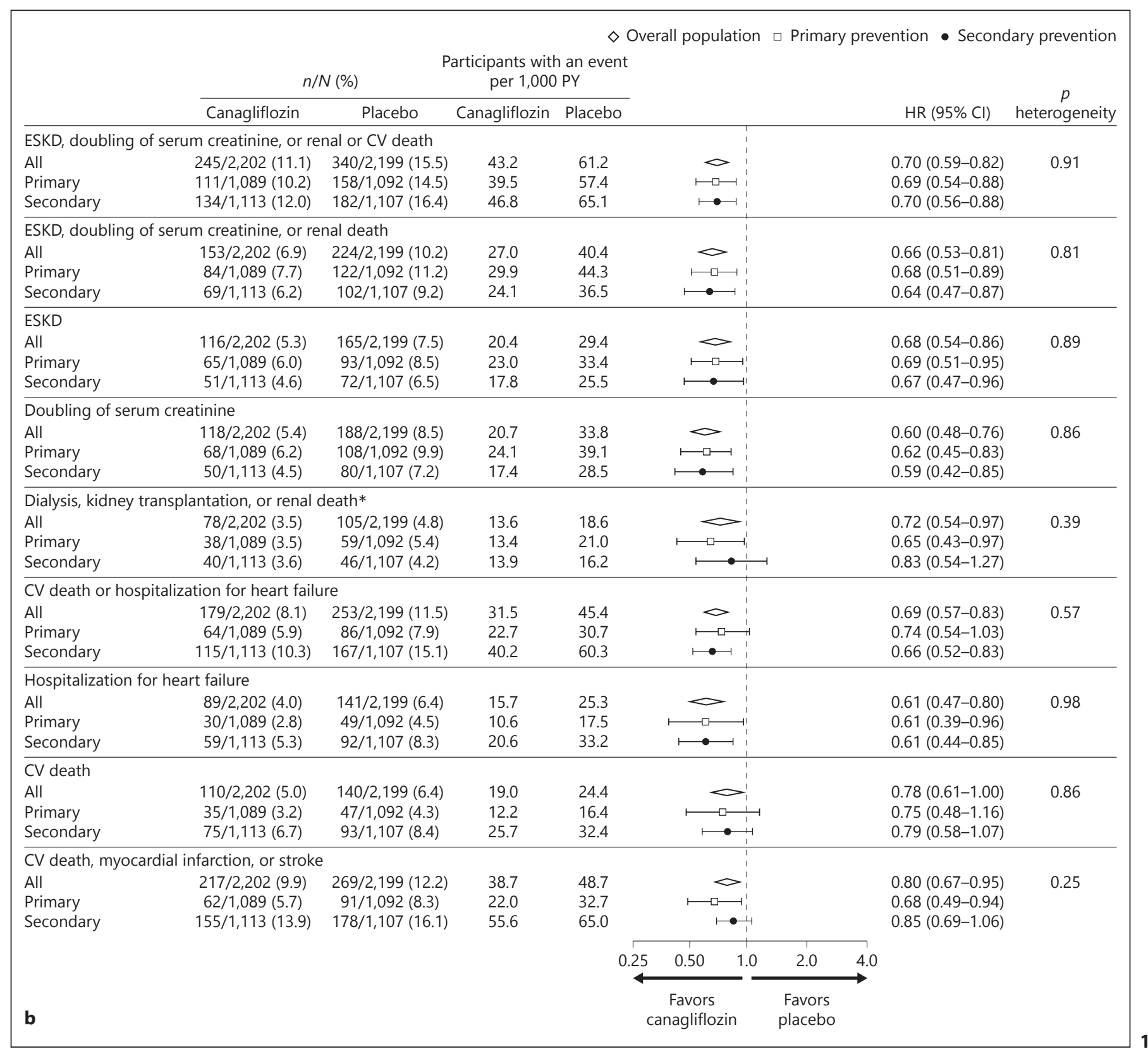

As expected, due to the acute hemodynamic effects of SGLT2 inhibition, there was a greater reduction in eGFR with canagliflozin than placebo over the first 3 weeks of treatment (between-group difference, $-3.17 \mathrm{~mL} / \mathrm{min} /$ $1.73 \mathrm{~m}^{2}$; Fig. 2) [43]. However, after the first 3 weeks, patients treated with canagliflozin had an approximately $60 \%$ slower annual rate of eGFR decline than with placebo $(-1.85$ vs. $-4.59 \mathrm{~mL} / \mathrm{min} / 1.73 \mathrm{~m}^{2}$, respectively; between-group difference, $2.74 \mathrm{~mL} / \mathrm{min} / 1.73 \mathrm{~m}^{2}$ ), suggesting that canagliflozin changes renal hemodynamics [43]. Off-treatment effects on eGFR were not tested in CREDENCE, but reversible acute effects of SGLT2 inhibitors on eGFR were demonstrated in EMPA-REG OUTCOME and CANVAS-R [27, 28].

Patients with later stages of CKD and T2DM have fragile health and are at high risk of renal and nonrenal complications [47], so higher rates of adverse events would be expected in CREDENCE compared with other clinical trials of SGLT2 inhibitors. The safety profile of canagliflozin in CREDENCE was generally similar to previous studies of canagliflozin. Overall, there were fewer adverse events (HR 0.87, 95\% CI 0.82-0.93) and serious adverse events (HR 0.87, 95\% CI 0.79-0.97) with canagliflozin 


\begin{tabular}{|c|c|c|c|c|c|c|c|}
\hline & \multicolumn{2}{|c|}{$n / N(\%)$} & \multicolumn{2}{|c|}{$\begin{array}{c}\text { Participants with an event } \\
\text { per } 1,000 \mathrm{PY}\end{array}$} & & & \multirow[b]{2}{*}{$\mathrm{HR}(95 \% \mathrm{Cl})$} \\
\hline & Canagliflozin & Placebo & Canagliflozin & Placebo & & & \\
\hline \multicolumn{8}{|c|}{ ESKD, doubling of serum creatinine, or renal or CV death } \\
\hline All & 245/2,202 (11.1) & $340 / 2,199(15.5)$ & 43.2 & 61.2 & $\infty \quad 1$ & & $0.70(0.59-0.82)$ \\
\hline $30-<45$ & $119 / 657(18.1)$ & $153 / 656(23.3)$ & 72.2 & 95.4 & $\bullet-1$ & & $0.75(0.59-0.95)$ \\
\hline \multicolumn{8}{|c|}{ ESKD, doubling of serum creatinine, or renal death } \\
\hline All & $153 / 2,202(6.9)$ & $224 / 2,199(10.2)$ & 27.0 & 40.4 & $\infty$ & & $0.66(0.53-0.81)$ \\
\hline $30-<45$ & $85 / 657(12.9)$ & $115 / 656(17.5)$ & 51.6 & 71.7 & $\longmapsto \hookrightarrow_{1}^{\prime}$ & & $0.71(0.53-0.94)$ \\
\hline \multicolumn{8}{|l|}{ ESKD } \\
\hline All & $116 / 2,202(5.3)$ & $165 / 2,199(7.5)$ & 20.4 & 29.4 & $\infty 1$ & & $0.68(0.54-0.86)$ \\
\hline $30-<45$ & $80 / 657(12.2)$ & $102 / 656(15.5)$ & 48.5 & 63.2 & $\longmapsto \quad$ & & $0.76(0.56-1.01)$ \\
\hline \multicolumn{8}{|c|}{ Doubling of serum creatinine } \\
\hline All & $118 / 2,202(5.4)$ & 188/2,199 (8.5) & 20.7 & 33.8 & $\propto \quad$ & & $0.60(0.48-0.76)$ \\
\hline $30-<45$ & $58 / 657(8.8)$ & $90 / 656(13.7)$ & 34.7 & 55.6 & $\longmapsto \longmapsto$ & & $0.61(0.44-0.85)$ \\
\hline \multicolumn{8}{|c|}{ Dialysis, kidney transplantation, or renal death* } \\
\hline All & 78/2,202 (3.5) & $105 / 2,199(4.8)$ & 13.6 & 18.6 & $\infty$ & & $0.72(0.54-0.97)$ \\
\hline $30-<45$ & $52 / 657(7.9)$ & $68 / 656(10.4)$ & 31.1 & 41.3 & $\longmapsto \quad 1$ & & $0.74(0.52-1.07)$ \\
\hline \multicolumn{8}{|c|}{ CV death or hospitalization for heart failure } \\
\hline All & $179 / 2,202(8.1)$ & 253/2,199 (11.5) & 31.5 & 45.4 & $\infty i$ & & $0.69(0.57-0.83)$ \\
\hline $30-<45$ & $68 / 657(10.4)$ & $97 / 656(14.8)$ & 40.7 & 59.1 & 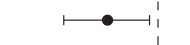 & & $0.69(0.50-0.94)$ \\
\hline \multicolumn{8}{|c|}{ Hospitalization for heart failure } \\
\hline All & $89 / 2,202(4.0)$ & $141 / 2,199(6.4)$ & 15.7 & 25.3 & $\infty \quad 1$ & & $0.61(0.47-0.80)$ \\
\hline $30-<45$ & $38 / 657(5.8)$ & $53 / 656(8.1)$ & 22.8 & 32.3 & $\longmapsto \quad 1$ & & $0.70(0.46-1.06)$ \\
\hline \multicolumn{8}{|l|}{ CV death } \\
\hline & $110 / 2,202(5.0)$ & $140 / 2,199(6.4)$ & 19.0 & 24.4 & $\infty i$ & & $0.78(0.61-1.00)$ \\
\hline $30-<45$ & $43 / 657(6.5)$ & $53 / 656(8.1)$ & 25.1 & 31.1 & $\longmapsto 1$ & & $0.81(0.54-1.21)$ \\
\hline \multicolumn{8}{|c|}{ CV death, myocardial infarction, or stroke } \\
\hline All & 217/2,202 (9.9) & 269/2,199 (12.2) & 38.7 & 48.7 & $\infty$ & & $0.80(0.67-0.95)$ \\
\hline \multirow[t]{2}{*}{$30-<45$} & $78 / 657(11.9)$ & $100 / 656(15.2)$ & 47.2 & 61.7 & $\longmapsto \quad$ & & $0.77(0.57-1.03)$ \\
\hline & & & & 0.25 & $0.50 \quad 1.0$ & $2.0 \quad 4.0$ & \\
\hline c & & & & & $\begin{array}{l}\text { Favors } \\
\text { canagliflozin }\end{array}$ & $\begin{array}{l}\text { Favors } \\
\text { placebo }\end{array}$ & \\
\hline
\end{tabular}

versus placebo [43]. The risk of renal-related adverse events was lower with canagliflozin versus placebo (HR 0.71, 95\% CI 0.61-0.82) and there was no difference in the risk of acute kidney injury (HR 0.85, 95\% CI 0.641.13). The risk of diabetic ketoacidosis was low in both groups, but higher with canagliflozin than placebo (2.2 vs. 0.2 events per 1,000 patient-years, respectively; HR 10.80 , 95\% CI 1.39-83.65); 11 of the 12 participants with diabetic ketoacidosis events were on insulin [43]. Consistent with previous studies, including the CANVAS Program, an increased risk of genital mycotic infections was seen with canagliflozin compared with placebo (males: HR 9.30, 95\% CI 2.83-30.60; females: HR 2.10, 95\% CI 1.00-4.45). There were no differences in risks of hyperkalemia, hypoglycemia, osmotic diuresis, or volume depletion events with canagliflozin versus placebo.

Increased risk of amputation and fracture were identified as safety signals in the CANVAS Program CVOT of canagliflozin [27]. The separation in amputation event rates between canagliflozin and placebo became apparent at $\sim 6$ months after randomization, but no specific cause, mechanism, or at-risk subgroup for increased amputation risk has been identified despite extensive post hoc analyses [48]. When the increased risk of amputation was identified in the CANVAS Program, a protocol amendment was introduced in CREDENCE that asked investigators to examine patients' feet at each trial visit, in accordance with good clinical practice, and to temporarily interrupt the assigned treatment in patients with any active condition that might lead to amputation [43]. CREDENCE participants had a higher baseline risk and rate of amputation than those in the CANVAS Program (5.3 vs. $2.3 \%$ with prior amputation at baseline, respectively) $[27,43]$. Consistent with the higher risk of amputation at baseline, placebo-treated participants had higher rates of amputation in CREDENCE than the CANVAS 
Fig. 2. Effects on eGFR in CREDENCE. Reprinted with permission from Perkovic et al. [43]. * Sixty percent reduction in the rate of eGFR decline with canagliflozin. eGFR, estimated glomerular filtration rate; CREDENCE, Canagliflozin and Renal Events in Diabetes with Established Nephropathy Clinical Evaluation; LS, least squares.

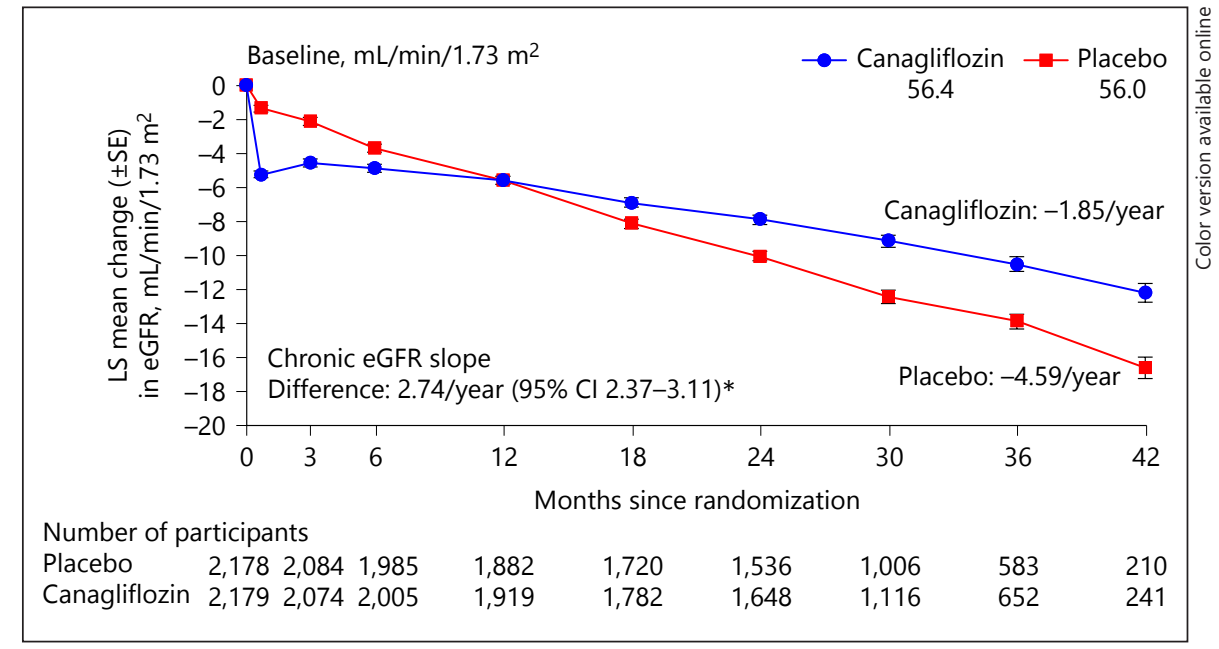

Program (11.2 and 3.4 events per 1,000 patient-years, respectively) [27, 43]. However, no difference in the risk of amputation was observed comparing canagliflozin- to placebo-treated patients in CREDENCE (12.3 vs. 11.2 events per 1,000 patient-years, respectively; HR 1.11, 95\% CI 0.79-1.56) over a mean follow-up time of 2.6 years $[27,43]$. In the CANVAS Program, an increased risk of fracture was seen in the CANVAS study, but not in CANVAS-R [27]. There was no difference in the risk of adjudicated fracture with canagliflozin versus placebo (11.8 vs. 12.1 events per 1,000 patient-years, respectively; HR $0.98,95 \%$ CI 0.70-1.37) [43], consistent with all but 1 trial of canagliflozin (the CANVAS study). Despite extensive post hoc analyses, no specific cause to explain this discrepancy has been identified, though an unidentified fall-related mechanism remains a possibility [49].

\section{Clinical Perspective}

The lack of new treatments for and increased prevalence of CKD over the last 2 decades has presented a challenge for both patients and physicians. The emergence of positive renal results from CREDENCE suggests that canagliflozin may have the therapeutic potential to substantially improve outcomes for people with T2DM and $\mathrm{CKD}$ on top of standard-of-care treatment with an ACE inhibitor or ARB. In real-world clinical practice, $5 \%$ of patients with T2DM would meet eligibility criteria for CREDENCE ( 2 million US adults; Fig. 3) [50, 51]. Although CVOTs provided some evidence of external validity in terms of renoprotection with SGLT2 inhibitors, CVOT participants had substantially better renal function than those in CREDENCE (Fig. 3); therefore, dedicated trials examining the risk of renal failure and death in patients with T2DM and CKD were needed to provide definitive evidence for the effects of SGLT2 inhibitors on renal outcomes and safety [40].

CREDENCE demonstrated that in patients with T2DM and CKD, treatment with canagliflozin significantly reduced the risk of doubling of serum creatinine, ESKD, or renal or CV death compared with placebo. Canagliflozin also reduced the risk of ESKD alone and CV endpoints, including the composite of $\mathrm{CV}$ death, myocardial infarction, or stroke and hospitalization for heart failure, suggesting that canagliflozin may provide both renal and $\mathrm{CV}$ protection for patients with T2DM and CKD, with and without prior atherosclerotic $\mathrm{CV}$ disease. As a result, the FDA has recently approved canagliflozin for reducing the risk of ESKD, doubling of serum creatinine, CV death, and hospitalization for heart failure in adults with T2DM and diabetic nephropathy with albuminuria [52].

CREDENCE provided the first-ever safety data of an SGLT2 inhibitor in patients with T2DM and CKD. Reassuringly, the overall safety profile of canagliflozin in CREDENCE was consistent with known adverse events, with no increased risk of hypoglycemia or acute kidney injury. Unlike the CANVAS Program, there were no imbalances between canagliflozin and placebo for amputation or fracture, indicating that although this population has a higher baseline risk of these outcomes, these are not safety concerns with canagliflozin for the population studied in CREDENCE when used in the manner studied - namely, good clinical practice with respect to diabetic foot care and peripheral artery disease including exclusion of patients with a history of traumatic amputa- 


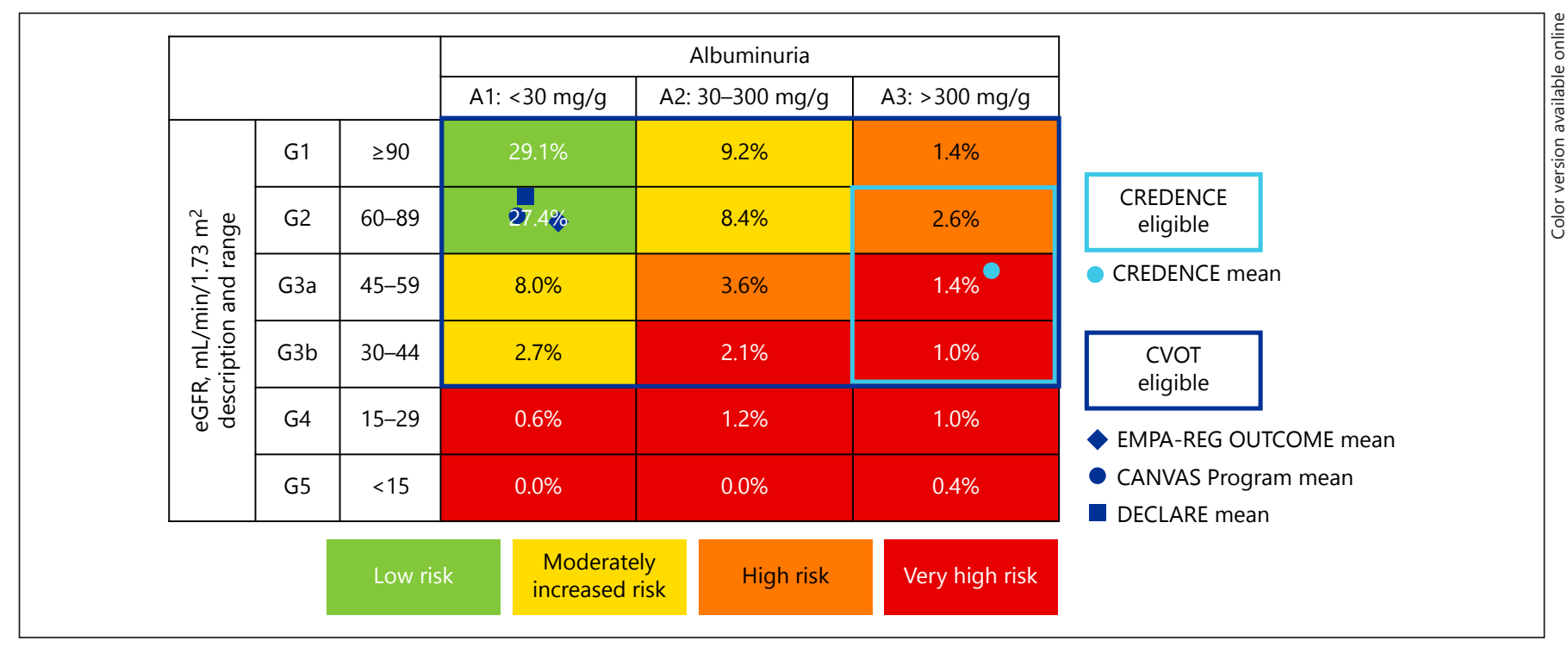

Fig. 3. Proportion of patients with T2DM and CREDENCE and CVOT eligibility by Kidney Disease: Improving Global Outcomes risk score. Proportion of patients with T2DM in each eGFR and UACR category based on US EHR data from Bailey et al. [50]. Position of mean eGFR and albuminuria shown for each trial are estimates. T2DM, type 2 diabetes mellitus; CREDENCE, Canagliflozin and Renal Events in Diabetes with Established

tion within 12 months, or an active foot ulcer, osteomyelitis, gangrene, or critical ischemia of the lower extremity within 6 months and interruption of therapy upon the emergence of any of the above with careful consideration of the individual risks and benefits prior to restarting canagliflozin after resolution of the event. Additionally, unlike studies of RAAS inhibitors, no increase in the risk of hyperkalemia was seen in CREDENCE, even on top of maximum-tolerated ACE inhibitor or ARB therapy.

However, there are some limitations associated with the study. Although CREDENCE was stopped early for efficacy at a planned interim analysis for the primary endpoint, the resulting follow-up time was relatively short (median of 2.6 years), which may have limited the power for some secondary outcomes and increased the risk of overestimating effect size [43].

The interest in the effects of antihyperglycemic agents in patients with CKD has led to plans for studies with other agents in people with and without T2DM [53-55]. The ongoing DAPA-CKD and EMPA-KIDNEY studies of dapagliflozin and empagliflozin will provide additional data on the potential for SGLT2 inhibitors to slow the progression of CKD in people with CKD with or without T2DM, and other studies will provide data on the effects of empagliflozin on hyperfiltration in patients with T1DM
Nephropathy Clinical Evaluation; CVOT, cardiovascular outcomes trial; eGFR, estimated glomerular filtration rate; UACR, urinary albumin-creatinine ratio; EMPA-REG OUTCOME, Empagliflozin, Cardiovascular Outcomes, and Mortality in Type 2 Diabetes; CANVAS, CANagliflozin cardioVascular Assessment Study; DECLARE, Dapagliflozin Effect in Cardiovascular Events.

$[53,54,56]$. Future studies could investigate whether therapy with canagliflozin and other agents, such as nonsteroidal mineralocorticoid receptor agonists, which are currently in development, could have synergistic effects in the kidney and heart [57].

Several mechanisms may contribute to the renal protective effects seen with canagliflozin, including reductions in HbAlc, body weight, BP, and albuminuria [58-63]. The effects of SGLT2 inhibitors on BP and body weight are independent of urinary glucose excretion [64-66]. However, data from CREDENCE suggest that the effects of canagliflozin on renal outcomes may be independent of effects on blood glucose, particularly because renoprotection is seen in patients with low eGFR levels who have negligible glucosuria [45, 67]. In addition, SGLT2 inhibitors have negligible long-term effects on serum potassium and an acute effect on serum creatinine that provides stable longterm benefits $[58,68]$. Furthermore, SGLT2 inhibition may confer renal protection via renal hemodynamic changes, such as attenuation of renal hyperfiltration and normalization of tubuloglomerular feedback by blocking sodium reabsorption at renal proximal tubules, thereby increasing sodium delivery to the macula densa $[62,69-72]$. In response, there is increased afferent arteriole tone, decreased glomerular hyperfiltration, and normalization of 
intraglomerular pressure $[62,70-72]$. The renal hemodynamic hypothesis is further supported by results of a study of empagliflozin in patients with T1DM [69] and by animal studies of empagliflozin and dapagliflozin [73, 74]. Global hemodynamic effects of SGLT2 inhibitors on interstitial fluid may also contribute to renoprotection. SGLT2 inhibition reduces interstitial fluid with minimal impact on blood volume and perfusion $[75,76]$. Another hypothesis has suggested that SGLT1 senses increased glucose in the macula densa, which increases production of nitric oxide, thereby blunting tubuloglomerular feedback and promoting glomerular hyperfiltration [77]. Additional putative renoprotective mechanisms have been postulated or proposed, which include reduction of albuminuria; reduction of glucose-mediated inflammation, proliferation, and fibrosis; proximal tubule hypertrophy; reduction of oxidative stress; and competitive inhibition of the family of sodium-hydrogen exchanger (NHE) channels in target organs including the heart and kidneys $[73,74,78-80]$. In addition, reductions in interstitial fluid and normalization of endothelial dysfunction may provide renal and CV protection $[66,75,76,81]$.

SGLT2 inhibitors may also contribute to renal protection through their effects on $\mathrm{CV}$ disease, including increases in lipolysis and ketogenesis, which change cellular energetics; increases in natriuresis and osmotic diuresis, which reduce pressure and volume overload; and offtarget inhibition of the NHE family of channels which are responsible for rapid restoration of intracellular $\mathrm{pH}[40$, 82-84]; and through favorable effects via NHE1 inhibition in ischemia-reperfusion [85]. In the kidney, SGLT2 inhibition may also inhibit NHE3 in the proximal tubule, with implications on natriuretic, GFR, and BP effects [86]. Another interesting mechanistic hypothesis is that the ketonemia among those treated with SGLT2 inhibitors may influence the relative utilization of glucose and fatty acids in cellular respiration that could be partially responsible for the observed CV and renal effects [87]. Details of these potential mechanisms are beyond the scope of this review.

SGLT2 inhibition may provide a more "user friendly" approach to kidney protection compared with RAAS inhibitors because there is less of a change in eGFR and limited to no effect on serum potassium. Thus, clinicians may be more likely to use these drugs, specifically in people with reduced kidney function. Based on data from CREDENCE, the American Diabetes Association guidelines were updated in June 2019 to suggest consideration of use of an SGLT2 inhibitor in patients with T2DM and CKD with eGFR $\geq 30 \mathrm{~mL} / \mathrm{min} / 1.73 \mathrm{~m}^{2}$ and particularly those with $>300 \mathrm{mg} / \mathrm{g}$ albuminuria to reduce the risk of
CKD progression, CV events, or both [16]. Treatment guidelines in Europe were recently updated to recommend SGLT2 inhibitors as first-line therapy in patients with T2DM who are at high risk of heart failure and for the prevention and management of CKD in patients who are at a high associated risk of CV disease [88]. In September 2019, the US prescribing information for canagliflozin was updated to allow initiation in people with eGFR $\geq 30 \mathrm{~mL} / \mathrm{min} / 1.73 \mathrm{~m}^{2}$ and continuation of treatment in those already on canagliflozin who reach eGFR $<30 \mathrm{~mL} / \mathrm{min} / 1.73 \mathrm{~m}^{2}$ and albuminuria $>300 \mathrm{mg} /$ day until initiation of dialysis or kidney transplantation [52]. These changes should work to broaden the population eligible for treatment to reduce the progression of CKD.

In conclusion, the CREDENCE trial provided evidence that patients with T2DM and CKD treated with canagliflozin have a lower risk of kidney failure and CV events compared with placebo with an acceptable safety profile. Data from additional dedicated outcomes trials in patients with CKD will be important to confirm whether renal benefits are a class effect of SGLT2 inhibitors and whether benefits may extend to patients with CKD without diabetes to build further evidence on the renal efficacy and safety of this class of drugs.

\section{Acknowledgements}

Medical writing support was provided by Dana Tabor, $\mathrm{PhD}$, of MedErgy, and was funded by Janssen Scientific Affairs, LLC.

\section{Statement of Ethics}

This review article does not contain new data from studies performed by the authors.

\section{Disclosure Statement}

M.R.W. has served on scientific advisory boards for Janssen, Boehringer Ingelheim, AstraZeneca, MSD, Relypsa, Vifor, AbbVie, and Boston Scientific; and is supported by grants from the National Institutes of Health (R01DK066013, U01DK106102, U01DK116095, R01HL127422, R01HL132732). P.A.M. has served as a consultant for Janssen, Boehringer Ingelheim, AstraZeneca, and MSD. J.B.B.'s contracted consulting fees are paid to the University of North Carolina by Adocia, AstraZeneca, Dance Biopharm, Dexcom, Eli Lilly, Fractyl, GI Dynamics, Intarcia Therapeutics, Lexicon, MannKind, Metavention, NovaTarg, Novo Nordisk, Orexigen, PhaseBio, Sanofi, Senseonics, vTv Therapeutics, and Zafgen; he reports grant support from AstraZeneca, Eli Lilly, Intarcia Therapeutics, Johnson \& Johnson, Lexicon, 
Medtronic, Novo Nordisk, Sanofi, Theracos, Tolerion, and vTv Therapeutics; he is a consultant to Cirius Therapeutics Inc., CSL Behring, Mellitus Health, Neurimmune AG, Pendulum Therapeutics, and Stability Health; he holds stock/options in Mellitus Health, Pendulum Therapeutics, PhaseBio, and Stability Health; and he is supported by grants from the National Institutes of Health (UL1TR002489, U01DK098246, UC4DK108612, U54DK118612), PCORI, and ADA. J.A. has served as a speaker for Eli Lilly, Novo Nordisk, Janssen, AstraZeneca, and Sanofi; on advisory boards or as a consultant for Eli Lilly, Novo Nordisk, AstraZeneca, Janssen, Sanofi, Abbott Diabetes, Merck, MannKind, and Zafgen; and on the board of directors for NuSirt BioPharma.

\section{Funding Sources}

This article was funded by Janssen Scientific Affairs, LLC. The sponsor was involved in the article conception, review of the manuscript draft, and decision to submit for publication.

\section{Author Contributions}

All authors contributed to the conception, drafting, and revision of the article. All authors approved the final version for submission.

\section{References}

1 Kidney Disease: Improving Global Outcomes CKD Working Group. KDIGO 2012 clinical practice guideline for the evaluation and management of chronic kidney disease. Kidney Int Suppl. 2013 Jan;3(1):1-150.

2 Coresh J. Update on the Burden of CKD. J Am Soc Nephrol. 2017 Apr;28(4):1020-2.

3 United States Renal Data System. Chapter 1: CKD in the general population. In: 2018 Annual Data Report [cited 2019 Feb 15]. Available from: https://www.usrds.org/2018/view/ v1_01.aspx.

4 Centers for Disease Control and Prevention. Chronic kidney disease basics [cited 2019 Mar 8]. Available from: https://www.cdc.gov/kidneydisease/basics.html.

5 Szczech LA, Stewart RC, Su HL, DeLoskey RJ, Astor BC, Fox CH, et al. Primary care detection of chronic kidney disease in adults with type- 2 diabetes: the ADD-CKD Study (awareness, detection and drug therapy in type 2 diabetes and chronic kidney disease). PLoS One. 2014 Nov;9(11):e110535.

6 Brenner BM, Cooper ME, de Zeeuw D, Keane WF, Mitch WE, Parving HH, et al.; RENAAL Study Investigators. Effects of losartan on renal and cardiovascular outcomes in patients with type 2 diabetes and nephropathy. $\mathrm{N}$ Engl J Med. 2001 Sep;345(12):861-9.

7 Lewis EJ, Hunsicker LG, Clarke WR, Berl T, Pohl MA, Lewis JB, et al.; Collaborative Study Group. Renoprotective effect of the angiotensin-receptor antagonist irbesartan in patients with nephropathy due to type 2 diabetes. $\mathrm{N}$ Engl J Med. 2001 Sep;345(12):851-60.

8 American Kidney Fund. Complications of CKD [cited 2019 Jul 10]. Available from: http://www.kidneyfund.org/kidney-disease/ chronic-kidney-disease-ckd/complications.

9 Thomas R, Kanso A, Sedor JR. Chronic kidney disease and its complications. Prim Care. 2008 Jun;35(2):329-44.

10 Mallat SG, Al Kattar S, Tanios BY, Jurjus A. Hyperuricemia, hypertension, and chronic kidney disease: an emerging association. Curr Hypertens Rep. 2016 Oct;18(10):74.

11 Miners JO, Yang X, Knights KM, Zhang L. The role of the kidney in drug elimination: transport, metabolism, and the impact of kidney disease on drug clearance. Clin Pharmacol Ther. 2017 Sep;102(3):436-49.

12 Alsahli M, Gerich JE. Hypoglycemia, chronic kidney disease, and diabetes mellitus. Mayo Clin Proc. 2014 Nov;89(11):1564-71.

13 Matsushita K, Ballew SH, Coresh J, Arima H, Ärnlöv J, Cirillo M, et al.; Chronic Kidney Disease Prognosis Consortium. Measures of chronic kidney disease and risk of incident peripheral artery disease: a collaborative meta-analysis of individual participant data. Lancet Diabetes Endocrinol. 2017 Sep;5(9): 718-28.

14 Tuttle KR, Bakris GL, Bilous RW, Chiang JL, de Boer IH, Goldstein-Fuchs J, et al. Diabetic kidney disease: a report from an ADA Consensus Conference. Diabetes Care. 2014 Oct; 37(10):2864-83.

15 Pálsson R, Patel UD. Cardiovascular complications of diabetic kidney disease. Adv Chronic Kidney Dis. 2014 May;21(3):273-80.

16 American Diabetes Association. 1. Improving care and promoting health in populations: Standards of Medical Care in Diabetes-2019. Diabetes Care. 2019 Jan;42(Suppl 1):S7-12.

17 COZAAR $^{\circledR}$ (losartan potassium) [package insert]. Merck Sharp \& Dohme Corp. Whitehouse Station, NJ: October 2018.

18 AVAPRO $^{\circledR}$ (irbesartan) [package insert]. Bristol-Myers Squibb. New York, NY: April 2011.

19 CAPOTEN $^{\circledR}$ (captopril tablets, USP) [package insert]. Par Pharmaceutical Companies, Inc. Spring Valley, NY: 2012.

20 Bavishi C, Bangalore S, Messerli FH. Renin angiotensin aldosterone system inhibitors in hypertension: is there evidence for benefit independent of blood pressure reduction? Prog Cardiovasc Dis. 2016 Nov-Dec;59(3):253-61.

21 Bakris GL, Weir MR. Angiotensin-converting enzyme inhibitor-associated elevations in serum creatinine: is this a cause for concern? Arch Intern Med. 2000 Mar;160(5): 685-93.

22 Vejakama P, Thakkinstian A, Lertrattananon D, Ingsathit A, Ngarmukos C, Attia
J. Reno-protective effects of renin-angiotensin system blockade in type 2 diabetic patients: a systematic review and network meta-analysis. Diabetologia. 2012 Mar;55(3): 566-78.

23 Nistor I, De Sutter J, Drechsler C, Goldsmith D, Soler MJ, Tomson C, et al. Effect of renin-angiotensin-aldosterone system blockade in adults with diabetes mellitus and advanced chronic kidney disease not on dialysis: a systematic review and meta-analysis. Nephrol Dial Transplant. 2018 Jan;33(1): 12-22.

24 Epstein M, Reaven NL, Funk SE, McGaughey KJ, Oestreicher N, Knispel J. Evaluation of the treatment gap between clinical guidelines and the utilization of renin-angiotensin-aldosterone system inhibitors. Am J Manag Care. 2015 Sep;21(11 Suppl):S212-20.

25 Vupputuri S, Kimes TM, Calloway MO, Christian JB, Bruhn D, Martin AA, et al. The economic burden of progressive chronic kidney disease among patients with type 2 diabetes. J Diabetes Complications. 2014 Jan-Feb; 28(1):10-6.

26 Wanner C. EMPA-REG OUTCOME: the nephrologist's point of view. Am J Med. 2017 Jun;130(6S):S63-72.

27 Neal B, Perkovic V, Mahaffey KW, de Zeeuw D, Fulcher G, Erondu N, et al.; CANVAS Program Collaborative Group. Canagliflozin and cardiovascular and renal events in type 2 diabetes. N Engl J Med. 2017 Aug;377(7): 644-57.

28 Zinman B, Wanner C, Lachin JM, Fitchett D, Bluhmki E, Hantel S, et al.; EMPA-REG OUTCOME Investigators. Empagliflozin, cardiovascular outcomes, and mortality in type 2 diabetes. N Engl J Med. 2015 Nov; 373(22):2117-28.

29 Wiviott SD, Raz I, Bonaca MP, Mosenzon O, Kato ET, Cahn A, et al.; DECLARE-TIMI 58 Investigators. Dapagliflozin and cardiovascular outcomes in type 2 diabetes. N Engl J Med. 2019 Jan;380(4):347-57.

30 Hartung EA. Biomarkers and surrogate endpoints in kidney disease. Pediatr Nephrol. 2016 Mar;31(3):381-91. 
31 Rosenstock J, Perkovic V, Johansen OE, Cooper ME, Kahn SE, Marx N, et al.; CARMELINA Investigators. Effect of linagliptin vs placebo on major cardiovascular events in adults with type 2 diabetes and high cardiovascular and renal risk: the CARMELINA randomized clinical trial. JAMA. 2019 Jan; 321(1):69-79.

32 Parving $\mathrm{HH}$, Brenner BM, McMurray JJ, de Zeeuw D, Haffner SM, Solomon SD, et al.; ALTITUDE Investigators. Cardiorenal end points in a trial of aliskiren for type 2 diabetes. N Engl J Med. 2012 Dec;367(23):220413.

33 Chin MP, Bakris GL, Block GA, Chertow GM, Goldsberry A, Inker LA, et al. Bardoxolone methyl improves kidney function in patients with chronic kidney disease stage 4 and type 2 diabetes: post-hoc analyses from bardoxolone methyl evaluation in patients with chronic kidney disease and type 2 diabetes study. Am J Nephrol. 2018 Jan;47(1): 40-7.

34 Pergola PE, Raskin P, Toto RD, Meyer CJ, Huff JW, Grossman EB, et al.; BEAM Study Investigators. Bardoxolone methyl and kidney function in CKD with type 2 diabetes. N Engl J Med. 2011 Jul;365(4):327-36.

35 Parving HH, Persson F, Lewis JB, Lewis EJ, Hollenberg NK; AVOID Study Investigators. Aliskiren combined with losartan in type 2 diabetes and nephropathy. N Engl J Med. 2008 Jun;358(23):2433-46.

36 Naresh CN, Hayen A, Weening A, Craig JC, Chadban SJ. Day-to-day variability in spot urine albumin-creatinine ratio. Am J Kidney Dis. 2013 Dec;62(6):1095-101.

37 Leong A, Ekinci EI, Nguyen C, Milne M, Hachem M, Dobson M, et al. Long-term intra-individual variability of albuminuria in type 2 diabetes mellitus: implications for categorization of albumin excretion rate. BMC Nephrol. 2017 Dec;18(1):355.

38 National Kidney Foundation. First reports from ambitious workshop published in The Lancet Diabetes and Endocrinology [cited 2019 Oct 22]. Available from: https://www. kidney.org/news/first-reports-ambitiouskidney-disease-clinical-trial-endpointsworkshop-to-be-published-lancet.

39 Levey AS, Inker LA, Matsushita K, Greene T, Willis $\mathrm{K}$, Lewis $\mathrm{E}$, et al. GFR decline as an end point for clinical trials in CKD: a scientific workshop sponsored by the National Kidney Foundation and the US Food and Drug Administration. Am J Kidney Dis. 2014 Dec; 64(6):821-35.

40 Kluger AY, Tecson KM, Barbin CM, Lee AY, Lerma EV, Rosol ZP, et al. Cardiorenal outcomes in the CANVAS, DECLARE-TIMI 58, and EMPA-REG OUTCOME trials: a systematic review. Rev Cardiovasc Med. 2018 Jun; 19(2):41-9.

41 McMurray JJ, Solomon SD, Inzucchi SE, Køber L, Kosiborod MN, Martinez FA, et al.; DAPA-HF Trial Committees and Investigators. Dapagliflozin in patients with heart fail- ure and reduced ejection fraction. N Engl J Med. 2019 Nov;381(21):1995-2008.

42 Jardine MJ, Mahaffey KW, Neal B, Agarwal R, Bakris GL, Brenner BM, et al.; CREDENCE Study Investigators. The Canagliflozin and Renal Endpoints in Diabetes with Established Nephropathy Clinical Evaluation (CREDENCE) study rationale, design, and baseline characteristics. Am J Nephrol. 2017 Dec; 46(6):462-72.

43 Perkovic V, Jardine MJ, Neal B, Bompoint S, Heerspink HJ, Charytan DM, et al.; CREDENCE Trial Investigators. Canagliflozin and renal outcomes in type 2 diabetes and nephropathy. N Engl J Med. 2019 Jun;380(24): 2295-306.

44 Mahaffey KW, Jardine MJ, Bompoint S, Cannon CP, Neal B, Heerspink HJ, et al. Canagliflozin and cardiovascular and renal outcomes in type 2 diabetes mellitus and chronic kidney disease in primary and secondary cardiovascular prevention groups. Circulation. 2019 Aug; 140(9):739-50.

45 Jardine MJ, Zhou Z, Mahaffey KW, Oshima M, Agarwal R, Bakris G, et al. Renal, cardiovascular, and safety outcomes of canagliflozin by baseline kidney function: a secondary analysis of the CREDENCE randomized trial. J Am Soc Nephrol. 2020; In press.

46 Bakris G, Oshima M, Mahaffey KW, Charytan DM, Levin A, Pollock C, et al. Canagliflozin slows declines in kidney function in people with baseline eGFR $<30 \mathrm{~mL} / \mathrm{min} / 1.73 \mathrm{~m}^{2}$. Presented at the American Society of Nephrology (ASN) Kidney Week 2019 Annual Meeting; November 5-10, 2019; Washington, DC.

47 Alicic RZ, Rooney MT, Tuttle KR. Diabetic kidney disease: challenges, progress, and possibilities. Clin J Am Soc Nephrol. 2017 Dec; 12(12):2032-45.

48 Matthews DR, Li Q, Perkovic V, Mahaffey KW, de Zeeuw D, Fulcher G, et al. Effects of canagliflozin on amputation risk in type $2 \mathrm{di}$ abetes: the CANVAS Program. Diabetologia. 2019 Jun;62(6):926-38.

49 Zhou Z, Jardine M, Perkovic V, Matthews DR, Mahaffey KW, de Zeeuw D, et al. Canagliflozin and fracture risk in individuals with type 2 diabetes: results from the CANVAS Program. Diabetologia. 2019 Oct;62(10): 1854-67.

50 Bailey RA, Wang Y, Zhu V, Rupnow MF. Chronic kidney disease in US adults with type 2 diabetes: an updated national estimate of prevalence based on Kidney Disease: Improving Global Outcomes (KDIGO) staging. BMC Res Notes. 2014 Jul;7(1):415.

51 Centers for Disease Control and Prevention. Chronic Kidney Disease in the United States, 2019 [cited 2019 Jul 9]. Available from: https://www.cdc.gov/kidneydisease/publications-resources/2019-national-facts.html.

52 INVOKANA (canagliflozin) tablets, for oral use [package insert]. Janssen Pharmaceuticals. Titusville, NJ: September 2019.

53 Boehringer Ingelheim, Medical Research Council Population Health Research Unit,
CTSU, University of Oxford (academic lead), Eli Lilly and Company: EMPA-KIDNEY (The Study of Heart and Kidney Protection With Empagliflozin). ClinicalTrials.gov Identifier: NCT03594110 [cited 2019 Feb 12] . Available from: https://clinicaltrials.gov/ct2/ show/NCT03594110.

54 AstraZeneca. A study to evaluate the effect of dapagliflozin on renal outcomes and cardiovascular mortality in patients with chronic kidney disease (Dapa-CKD) [cited $2018 \mathrm{Feb}$ 1]. Available from: https://clinicaltrials.gov/ ct $2 /$ show/NCT03036150.

55 Novo Nordisc A/S. A research study to see how semaglutide works compared to placebo in people with type 2 diabetes and chronic kidney disease (FLOW) [cited 2019 Mar 21]. Available from: https://clinicaltrials.gov/ct2/ show/NCT03819153.

56 Boehringer Ingelheim, Eli Lilly and Company. Empagliflozin and ACEi- effects on hyperfiltration: BETWEEN Study [cited 2019 Sep 9]. Available from: https://clinicaltrials. gov/ct2/show/NCT02632747.

57 Capelli I, Gasperoni L, Ruggeri M, Donati G, Baraldi O, Sorrenti G, et al. New mineralocorticoid receptor antagonists: update on their use in chronic kidney disease and heart failure. J Nephrol. 2020 Feb;33(1):37-48.

58 Rosenthal N, Meininger G, Ways K, Polidori D, Desai M, Qiu R, et al. Canagliflozin: a sodium glucose co-transporter 2 inhibitor for the treatment of type 2 diabetes mellitus. Ann N Y Acad Sci. 2015 Nov; 1358(1):2843.

59 Anderson SL, Marrs JC. Dapagliflozin for the treatment of type 2 diabetes. Ann Pharmacother. 2012 Apr;46(4):590-8.

60 Levine MJ. Empagliflozin for type 2 diabetes mellitus: an overview of phase 3 clinical trials. Curr Diabetes Rev. 2017;13(4):405-23.

61 Anders HJ, Davis JM, Thurau K. Nephron protection in diabetic kidney disease. N Engl J Med. 2016 Nov;375(21):2096-8.

62 Weir MR. The kidney and type 2 diabetes mellitus: therapeutic implications of SGLT2 inhibitors. Postgrad Med. 2016;128(3):290-8.

63 Mende CW. Diabetes and kidney disease: the role of sodium-glucose cotransporter-2 (SGLT-2) and SGLT-2 inhibitors in modifying disease outcomes. Curr Med Res Opin. 2017 Mar;33(3):541-51.

64 Blonde L, Stenlöf K, Fung A, Xie J, Canovatchel W, Meininger G. Effects of canagliflozin on body weight and body composition in patients with type 2 diabetes over 104 weeks. Postgrad Med. 2016 May;128(4):37180.

65 Perkovic V, Jardine M, Vijapurkar U, Meininger G. Renal effects of canagliflozin in type 2 diabetes mellitus. Curr Med Res Opin. 2015 Dec;31(12):2219-31.

66 Sternlicht H, Bakris GL. Blood pressure lowering and sodium-glucose co-transporter 2 inhibitors (SGLT2is): more than osmotic diuresis. Curr Hypertens Rep. 2019 Feb;21(2): 12. 
67 Charytan DM, Mahaffey KW, Jardine M, Agarwal R, Bull S, Chu PL, et al. Renoprotective effects of canagliflozin in CREDENCE may be independent of glucose-lowering mechanisms. Presented at the American Society of Nephrology (ASN) Kidney Week 2019 Annual Meeting; November 5-10, 2019; Washington, DC

68 Weir MR, Kline I, Xie J, Edwards R, Usiskin $\mathrm{K}$. Effect of canagliflozin on serum electrolytes in patients with type 2 diabetes in relation to estimated glomerular filtration rate (eGFR). Curr Med Res Opin. 2014 Sep;30(9): 1759-68.

69 Cherney DZ, Perkins BA, Soleymanlou N, Maione M, Lai V, Lee A, et al. Renal hemodynamic effect of sodium-glucose cotransporter 2 inhibition in patients with type 1 diabetes mellitus. Circulation. 2014 Feb;129(5):587-97.

70 Muskiet MH, Tonneijck L, van Bommel EJ, Smits MM, van Raalte DH. Renoprotection in LEADER and EMPA-REG OUTCOME. Lancet Diabetes Endocrinol. 2016 Oct;4(10):8124.

71 Perrone-Filardi P, Avogaro A, Bonora E, Colivicchi F, Fioretto P, Maggioni AP, et al. Mechanisms linking empagliflozin to cardiovascular and renal protection. Int J Cardiol. 2017 Aug;241:450-6.

72 Fioretto P, Zambon A, Rossato M, Busetto L, Vettor R. SGLT2 inhibitors and the diabetic kidney. Diabetes Care. 2016 Aug;39(Suppl 2): S165-71.

73 Vallon V, Gerasimova M, Rose MA, Masuda T, Satriano J, Mayoux E, et al. SGLT2 inhibitor empagliflozin reduces renal growth and albuminuria in proportion to hyperglycemia and prevents glomerular hyperfiltration in diabetic Akita mice. Am J Physiol Renal Physiol. 2014 Jan;306(2):F194-204.

74 Terami N, Ogawa D, Tachibana H, Hatanaka T, Wada J, Nakatsuka A, et al. Long-term treatment with the sodium glucose cotransporter 2 inhibitor, dapagliflozin, ameliorates glucose homeostasis and diabetic nephropa- thy in $\mathrm{db} / \mathrm{db}$ mice. PLoS One. 2014 Jun;9(6): e100777.

75 Verma S, McMurray JJ. SGLT2 inhibitors and mechanisms of cardiovascular benefit: a stateof-the-art review. Diabetologia. 2018 Oct; 61(10):2108-17.

76 Hallow KM, Helmlinger G, Greasley PJ, McMurray JJ, Boulton DW. Why do SGLT2 inhibitors reduce heart failure hospitalization? A differential volume regulation hypothesis. Diabetes Obes Metab. 2018 Mar;20(3):479-87.

77 Zhang J, Wei J, Jiang S, Xu L, Wang L, Cheng F, et al. Macula densa SGLT1-NOS1-tubuloglomerular feedback pathway, a new mechanism for glomerular hyperfiltration during hyperglycemia. J Am Soc Nephrol. 2019 Apr; 30(4):578-93.

78 Osorio H, Coronel I, Arellano A, Pacheco U, Bautista R, Franco M, et al. Sodium-glucose cotransporter inhibition prevents oxidative stress in the kidney of diabetic rats. Oxid Med Cell Longev. 2012 Nov;2012:542042.

79 Woods TC, Satou R, Miyata K, Katsurada A, Dugas CM, Klingenberg NC, et al. Canagliflozin prevents intrarenal angiotensinogen augmentation and mitigates kidney injury and hypertension in mouse model of type 2 diabetes mellitus. Am J Nephrol. 2019;49(4): 331-42.

80 de Albuquerque Rocha N, Neeland IJ, McCullough PA, Toto RD, McGuire DK. Effects of sodium glucose co-transporter 2 inhibitors on the kidney. Diab Vasc Dis Res. 2018 Sep;15(5):375-86.

81 Herat LY, Magno AL, Rudnicka C, Hricova J, Carnagarin R, Ward N, et al. SGLT2 inhibitor induced sympatho-inhibition-a novel mechanism for cardiorenal protection. J Am Coll Cardiol. 2019; In press.

82 Novikov A, Vallon V. Sodium glucose cotransporter 2 inhibition in the diabetic kidney: an update. Curr Opin Nephrol Hypertens. 2016 Jan;25(1):50-8.

83 Lytvyn Y, Bjornstad P, Udell JA, Lovshin JA, Cherney DZ. Sodium glucose cotransporter- 2 inhibition in heart failure: potential mechanisms, clinical applications, and summary of clinical trials. Circulation. 2017 Oct;136(17): 1643-58.

84 McCullough PA, Kluger AY, Tecson KM, Barbin CM, Lee AY, Lerma EV, et al. Inhibition of the sodium-proton antiporter (exchanger) is a plausible mechanism of potential benefit and harm for drugs designed to block sodium glucose co-transporter 2 . Rev Cardiovasc Med. 2018 Jun;19(2):51-63.

85 Uthman L, Baartscheer A, Bleijlevens B, Schumacher CA, Fiolet JW, Koeman A, et al. Class effects of SGLT2 inhibitors in mouse cardiomyocytes and hearts: inhibition of $\mathrm{Na}^{+} /$ $\mathrm{H}^{+}$exchanger, lowering of cytosolic $\mathrm{Na}^{+}$and vasodilation. Diabetologia. 2018 Mar;61(3): 722-6.

86 Vallon V, Thomson SC. Targeting renal glucose reabsorption to treat hyperglycaemia: the pleiotropic effects of SGLT2 inhibition. Diabetologia. 2017 Feb;60(2):215-25.

87 Ferrannini E, Baldi S, Frascerra S, Astiarraga $\mathrm{B}$, Barsotti E, Clerico A, et al. Renal handling of ketones in response to sodium-glucose cotransporter 2 inhibition in patients with type 2 diabetes. Diabetes Care. 2017 Jun;40(6): 771-6.

88 Cosentino F, Grant PJ, Aboyans V, Bailey CJ, Ceriello A, Delgado V, et al.; ESC Scientific Document Group. 2019 ESC Guidelines on diabetes, pre-diabetes, and cardiovascular diseases developed in collaboration with the EASD. Eur Heart J. 2020 Jan;41(2):255323

89 Wanner C, Inzucchi SE, Zinman B. Empagliflozin and progression of kidney disease in type 2 diabetes. N Engl J Med. 2016 Nov; 375(18):1801-2.

90 Perkovic V, de Zeeuw D, Mahaffey KW, Fulcher G, Erondu N, Shaw W, et al. Canagliflozin and renal outcomes in type 2 diabetes: results from the CANVAS Program randomised clinical trials. Lancet Diabetes Endocrinol. 2018 Sep;6(9):691-704. 